\title{
LONG-TERM Graft FunCtion of CRYOstored Alginate ENCAPSULATED RAT ISLETS
}

\author{
Stephan Schneider ${ }^{1,2}$, Harald H. Klein ${ }^{1}$ \\ ${ }^{1}$ Department of Internal Medicine I, Division of Endocrinology and Metabolism, \\ Berufsgenossenschaftliches University Hospital Bergmannsheil, Ruhr-University Bochum, Bochum, Germany \\ ${ }^{2}$ Department of Internal Medicine II, Diabetology and Endocrinology, St. Vinzenz-Hospital, Cologne, Germany
}

\begin{abstract}
Microencapsulation of pancreatic islets before transplantation is a promising approach to enable graft function in an immunocompetent recipient without immunosuppression. However, the insufficient availability of allogenic islet tissue is a major problem. One concept to overcome these shortcomings is the cryopreservation of encapsulated allogenic islets. Recently, we reported a gentle cryopreservation protocol for rat islets encapsulated in an alginate-based microcapsule system. Here, we report for the first time long-term transplantation data of these cryopreserved microencapsulated islets. We detected a stable graft function for more than 12 month (experiments still continuing) after transplantation of 2500 cryopreserved microencapsulated CD rat islets in streptozotocin-diabetic Wistar rats. Moreover, the glucose clearance rate during an IPGT'T was well preserved up to 56 weeks after transplantation. In addition, hyperglycemic blood glucose levels after removal of rat islet grafts 12 and 56 weeks after transplantation confirmed the efficacy of the encapsulated islets. Finally, the retrieved encapsulated rat islets responded well with a 7 -fold increase of insulin secretion to a glucose stimulus (12 and 56 weeks). In conclusion, our study demonstrates for the first time that cryopreservation of encapsulated rat islets is possible without substantial losses on graft function for a very long time.
\end{abstract}

Key words: rat islets, alginate capsules, transplantation, cryopreservation, insulin secretion

\section{INTRODUCTION}

Islet transplantation is one concept to cure patients with type 1 diabetes $[1,2]$. However, one drawback of islet transplantation is that this technique requires the administration of immuno $\neg$ sup $\neg$ pressiva that may be associated with serious side effects, e.g. loss of kidney function [2]. Moreover, these drugs directly impair beta-cell function and reduce the regenerative capacity of islet tissue [3]. We and others have shown that a bioartificial pancreas consisting of islets immunoprotected by an alginate microcapsule provides a very promising approach to overcome the rejection problem [4-8]. However, as with non-encapsulated allo- genic islets, the problem of islet tissue shortage still exists. This is aggravated, because microcapsules are floating freely in the peritoneal cavity without any vascularisation. Therefore, $4-5$ times higher islet cell masses are needed to guarantee normoglycemia compared to non-encapsulated islets transplanted intraportally [4]. A reasonable concept to overcome these shortcomings is the cryopreservation and subsequent storage of microencapsulated allogenic islets, to allow their unlimited collection and use on demand. In this line of reasoning, recently we published a cryopreservation protocol for encapsulated islets with promising short-term transplantation data (4 weeks) [9]. However, before a clinical application of these cryopreserved immunoprotected transplants seems to be reasonable, long-term functionality data in vivo are highly warranted. Therefore, here we report for the first time long-term transplantation outcome data for these cryopreserved encapsulated islet cells.

\section{Materials And Methods}

\section{Isolation of rat islets}

Pancreatic islets were isolated from male CD rats (Charles River, Sulzfeld, Germany) with a body weight of $250-270 \mathrm{~g}$ and $6-8$ weeks of age, as described previously $[4,9]$. Briefly, the rats were anaesthetised by intraperitoneal pentobarbital administration $(60$ $\mathrm{mg} / \mathrm{kg}$ ). Then a midline abdominal incision was performed, the pancreas was exposed and injected via the pancreatic duct with Hank's balanced salt solution (HBSS; Biochrom KG, Berlin, Germany) containing $0.5 \mathrm{mg} / \mathrm{ml}$ collagenase (Serva PanPlus, Heidelberg, Germany). After sacrificing the animal, the pancreatic tissue was surgically removed and incubated for $7 \mathrm{~min}$ at $37^{\circ} \mathrm{C}$ in the collagenase solution. Mechanical disruption of the digested pancreatic tissue was achieved by further incubation in collagenase solution at $37^{\circ} \mathrm{C}$ for $7 \mathrm{~min}$, interrupted every 80 seconds by shaking for 15 seconds. Digestion was stopped by addition of $4{ }^{\circ} \mathrm{C}$-cold HBSS plus $10 \%$ fetal calf serum (FCS; Greiner Laboratories, Frickenhausen, Germany). Islet purification was achieved using a discontinuous threephase Ficoll density gradient (densities: 1.090, 1.077 and 1.040). Before encapsulation and cryopreservation islets were cultured overnight in RPMI-1640 medium 
at $37{ }^{\circ} \mathrm{C}$ in a humidified atmosphere of $95 \%$ air and $5 \% \mathrm{CO}_{2}$. The medium was supplemented with 5.1 mmol/1 glucose, 10\% FCS, $0.2 \mathrm{~g} / 1$ Glutamax, 200 $\mathrm{U} / \mathrm{ml}$ penicillin, $200 \mu \mathrm{g} / \mathrm{ml}$ streptomycin (Gibco BRL, Paisley, Scotland, GB) and $50 \mu \mathrm{g} / \mathrm{ml}$ ciprofloxacin (Bayer, Leverkusen, Germany).

\section{Islet encapsulation}

Microencapsulation was performed by using ultra-high viscosity alginate of clinical grade [4]. Briefly, for microcapsule formation the alginate was dissolved in sterile, endotoxin-free $0.9 \%$ physiologic saline solution at a concentration of $0.7 \%(\mathrm{w} / \mathrm{v})$. Human serum albumin (3\% HSA; Pharmacia, Erlangen, Germany) was added to the alginate solution before cross-linking. For microcapsule formation a two-channel air jet droplet generator was used. The islet containing microcapsules were dropped into a $20 \mathrm{mM} \mathrm{BaCl}$ solution adjusted to $290 \mathrm{mOsm}$ with appropriate amounts of $\mathrm{NaCl}$ and buffered to $\mathrm{pH} 7$ with $5 \mathrm{mM}$ histidine. After $20 \mathrm{~min}$, the islet containing microcapsules were washed three times with physiologic saline solution and then treated with $6 \mathrm{mM}$ Na2SO4 saline solution for $30 \mathrm{~min}$ at 37 ${ }^{\circ} \mathrm{C}$ to precipitate excess $\mathrm{Ba}^{2+}$ ions. The microcapsules obtained by this en $\neg$ capsulation procedure had a diameter of approximately $700-800 \mu \mathrm{m}$ and contained on average one islet, in rare cases two or three.

\section{Cryopreservation}

Microencapsulated CD rat islets were cryopreserved with a protocol described previously [9]. Briefly, immediately after encapsulation $\sim 500$ microencapsulated islets were transferred into a cryovial $(2 \mathrm{ml})$ and re-suspended in $0.2 \mathrm{ml}$ of RPMI plus $10 \%$ FCS. Thereafter, the cryoprotectant dimethyl sulfoxide (DMSO = $\mathrm{Me}_{2} \mathrm{SO}$ ) was added in a stepwise manner, starting with $0.1 \mathrm{ml}$ of $2.0 \mathrm{M} \mathrm{DMSO}$ for $5 \mathrm{~min}$ at $0^{\circ} \mathrm{C}$, followed by $0.1 \mathrm{ml}$ of $2.0 \mathrm{M} \mathrm{DMSO}$ for $5 \mathrm{~min}$ at $0^{\circ} \mathrm{C}$ and finally $0.4 \mathrm{ml} 3.1 \mathrm{M}$ DMSO for $5 \mathrm{~min}$ at $0^{\circ} \mathrm{C}$. When this prefreezing phase was finished the cryovials were transferred into the chamber of a computer-controlled freezing machine (BV-8, Consarctic, Heidelberg, Germany). When the freezing program had been completed the cryovials were transferred into liquid nitrogen. After storage in liquid nitrogen for at least 7 days, cryovials with frozen islets were plunged into a water bath maintained at $37^{\circ} \mathrm{C}$ and rapidly thawed to $0{ }^{\circ} \mathrm{C}$ at a rate of approximately $200^{\circ} \mathrm{C} / \mathrm{min}$. Thereafter, DMSO was removed from the islets by repeated additions of $0.75 \mathrm{M}$ sucrose solution in a stepwise manner (adding $0.17 \mathrm{ml}$ every $5 \mathrm{~min}$ for a period of $30 \mathrm{~min}$ ).

\section{Animals}

Male Wistar rats (Charles River, Sulzfeld, Germany) 6 -8 weeks old, were used as recipients for microencapsulated islets. Two weeks before transplantation rats were rendered diabetic via intraperitoneal injections of streptozotocin $(60 \mathrm{mg} / \mathrm{kg}$ body weight; Sigma Aldrich, Steinheim, Germany) freshly dissolved in citrate buffer. Only animals exhibiting blood sugar concentrations greater than $350 \mathrm{mg} / \mathrm{dl}$ in four consecutive measurements were used as recipients. All animal studies were approved by the Landesamt für Naturschutz (Recklinghausen, Germany, No. 50.10.32.08.037).

\section{Transplantation of islets}

Transplants were made under sterile conditions. Cryostored microencapsulated rat islets were injected into the peritoneal cavity by using a 20 gauge needle (Vasofix ${ }^{\circledR}$, Braun, Melsungen, Germany). Before treatment the Wistar rats were anaesthetized by intraperitoneal pentobarbital administration $(50 \mathrm{mg} / \mathrm{kg}$ ). Each rat $(\mathrm{n}=14)$ received 2500 cryostored encapsulated rat islets. Control animals received the same number of either non-cryostored non-encapsulated ( $n=14$ ) or non-cryostored encapsulated $(\mathrm{n}=14)$ rat islets, respectively.

\section{Intraperitoneal glucose tolerance test (IPGTT)}

After transplantation plasma glucose levels of islet recipients were monitored biweekly. Blood samples were taken from the tail vein under non-fasting conditions (8 a.m.; standard laboratory chow ad libitum overnight) and plasma glucose levels were determined by means of the glucose-oxidase method with a clinical analyzer (Nova Biomedical, Rödermark, Germany). The rats were considered to be normoglycemic when the plasma glucose levels were lower than $200 \mathrm{mg} / \mathrm{dl}$. An IPGT'T was performed in fasting (12 hours), unanaesthetized rats transplanted with cryostored or control (fresh, non-cryostored) microencapsulated rat islets 2 , 12 and 56 weeks after transplantation, using a 5\% glucose solution ( $2 \mathrm{~g} / \mathrm{kg}$ body weight). Plasma glucose levels were measured at 0, 30, 60 and 120 minutes.

\section{Microcapsule explantation}

Grafts were retrieved from animals which received non-cryostored encapsulated rat islets $(\mathrm{n}=3$ at 12 weeks and $n=3$ at 56 weeks after transplantation) and cryostored encapsulated rat islets ( $\mathrm{n}=3$ at 12 weeks and $\mathrm{n}=3$ at 56 weeks after transplantation). Under anaesthesia a $2-\mathrm{cm}$ incision was made in the abdomen and capsules were explanted by repeated flushes with warmed $0.9 \% \mathrm{NaCl}$ solution. The abdomen was sutured and the animals checked daily for blood glucose concentrations.

\section{Assessment of insulin secretion by a static incubation assay}

The static incubation assay was used to assess the insulin secretion response of non-cryostored non-encapsulated (control), non-cryostored encapsulated (control) or cryostored encapsulated islets after a glucose challenge both before transplantation and after retrieval of the capsules [9]. 10 samples of 10 cryostored or control islets of equal size and shape were handpicked and transferred into a culture-insert (membrane pore diameter $12 \mu \mathrm{m}$; Millicell PCF, Millipore, France). The insert was put into a well of a 24-well culture-plate (Falcon Multiwell, Becton Dickinson, USA). Basal insulin secretion was measured after 1.5 hour incubation at $37^{\circ} \mathrm{C}$ in RPMI $1640+\mathrm{D}$-glucose $1 \mathrm{~g} / 1+3 \%$ HSA. Then the inserts with islets were transferred into hyperglycemic culture-media (RPMI $1640+$ D-glucose 3 $\mathrm{g} / 1+3 \% \mathrm{HSA}$ ) for further 1.5 hours. Aliquots of the media were stored at $-20^{\circ} \mathrm{C}$ after removal of the inserts. Rat insulin was measured with the rat-insulin ELISA (Mercodia, Uppsala, Sweden). Results are given in $\mathrm{ng} /$ islet/1.5h for rat islets. 
Statistics. Values are given as mean \pm SE. Statistical significance of differences was calculated with an unpaired Student's t-test (two-sided). All calculations have been performed with KaleidaGraph 4.0.3 for Macintosh Computers (Synergy Software, Reading, PA. USA).

\section{RESULTS}

\section{Graft survival}

Prior to transplantation, the insulin secretion capacity of non-cryostored and cryostored encapsulated islets cultured for one day was determined. As shown in Table 1, non-cryostored and crystored encapsulated CD rat islets responded well to a high glucose stimulus. The insulin increase upon a glucose challenge was comparable to that of the corresponding non-encapsulated islets, even though the absolute amount of insulin was lower, presumably due to diffusion restrictions within the cross-linked alginate matrix. Transplantation of 2500 non-encapsulated CD rat islets into the peritoneal cavity of diabetic Wistar rats resulted in normoglycemia for about 6 to 9 days. In contrast, when non-crystored or cryostored encapsulated rat islets were transplanted under the same conditions normoglycemia was achieved for more than 360 days (Table 2). Normoglycemic blood sugar levels were generally reached within $24 \mathrm{~h}$ of transplantation. Graft explantation from animals transplanted with non- cryostored or cryostored encapsulated islets 12 and 56 weeks after transplantation resulted immediately in the reappearance of hyperglycaemia associated with blood glucose concentrations above $500 \mathrm{mg} / \mathrm{dl}$. Taken together, transplantation of cryostored as well as of non-crystored encapsulated islets in immunocompetent rats enables stable graft function without the need of immunosuppression.

IPGTTs

Figure 1 illustrates the blood glucose profiles of Wistar rats transplanted with non- cryostrored and cryostored microencapsulated CD rat islets during IPGTTs 2, 12 and 56 weeks after transplantation. As indicated, rats transplanted with cryostored encapsulated rat islets showed the same blood glucose concentration after overnight fasting (time zero) as the rats transplanted with non-cryostored encapsulated islets (controls). More importantly, the subsequent glucose clearance kinetics up to $120 \mathrm{~min}$ were comparable. Taken together, transplantation of cryostored and non-cryostored encapsulated islets in immunocompetent rats leads to normal glucose clearance kinetics up to 56 weeks after transplantation.

Retrieved microcapsules

Consistent with the results of the IPGT'Ts the retrieved encapsulated rat islets responded well to a glucose challenge (Table 1).

Table 1. Insulin secretion of non-cryopreserved non-encapsulated, non-cryopreserved encapsulated and cryopreserved encapsulated rat islets in a static incubation assay before, 12 and 56 weeks after transplantation.

\begin{tabular}{|l|c|c|c|c|c|c|}
\hline & \multicolumn{2}{|c|}{ Non-encapsulated } & \multicolumn{2}{c|}{$\begin{array}{c}\text { Non-cryopreserved } \\
\text { encapsulated }\end{array}$} & \multicolumn{2}{c|}{$\begin{array}{c}\text { Cryopreserved } \\
\text { encapsulated }\end{array}$} \\
\hline Time & $\begin{array}{c}\text { Basal } \\
(\mathrm{ng} / \mathrm{islet} / 1,5 \mathrm{~h})\end{array}$ & $\begin{array}{c}\text { Stimulated } \\
(\mathrm{ng} / \text { islet/1,5h) }\end{array}$ & $\begin{array}{c}\text { Basal } \\
(\mathrm{ng} / \text { islet/1,5h) }\end{array}$ & $\begin{array}{c}\text { Stimulated } \\
(\mathrm{ng} / \mathrm{islet} / 1,5 \mathrm{~h})\end{array}$ & $\begin{array}{c}\text { Basal } \\
(\mathrm{ng} / \mathrm{islet} / 1,5 \mathrm{~h})\end{array}$ & $\begin{array}{c}\text { Stimulated } \\
(\mathrm{ng} / \mathrm{islet} / 1,5 \mathrm{~h})\end{array}$ \\
\hline before & $2.9 \pm 1.0$ & $22.1 \pm 5.5$ & $2.1 \pm 0.3$ & $15.8 \pm 4.6$ & $2.0 \pm 0.6$ & $16.5 \pm 4.0$ \\
\hline *12 weeks & - & - & $1.8 \pm 0.5$ & $15.1 \pm 2.7$ & $2.0 \pm 0.7$ & $14.9 \pm 2.1$ \\
\hline *56 weeks & - & - & $1.9 \pm 0.6$ & $15.7 \pm 4.3$ & $2.2 \pm 0.4$ & $15.1 \pm 4.3$ \\
\hline
\end{tabular}

Data are given as mean $\pm \mathrm{SE} ; \mathrm{n}=3$ independent experiments; $*$ Measurements were performed after retrieval

Table 2. Graft function of non-encapsulated non-cryopreserved, non-cryopreserved encapsulated and cryopreserved encapsulated $\mathrm{CD}$ rat islets transplanted into the peritoneal cavity of diabetic Wistar rats.

\begin{tabular}{|c|c|c|c|}
\hline Transplant Recipient & Islet Donor & Treatment & Time of graft function (d) \\
\hline Wistar rat & CD Rat & None & $6.8 \pm 1.8$ \\
\hline Wistar rat & CD Rat & Microcapsules & 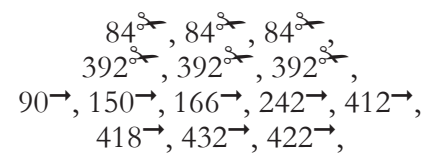 \\
\hline Wistar rat & $\mathrm{CD}$ rat & $\begin{array}{l}\text { Cryopreservation } \\
\text { Microcapsules }\end{array}$ & 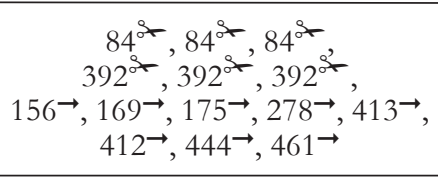 \\
\hline
\end{tabular}

of Time of explantation, $\rightarrow$ ongoing graft function 


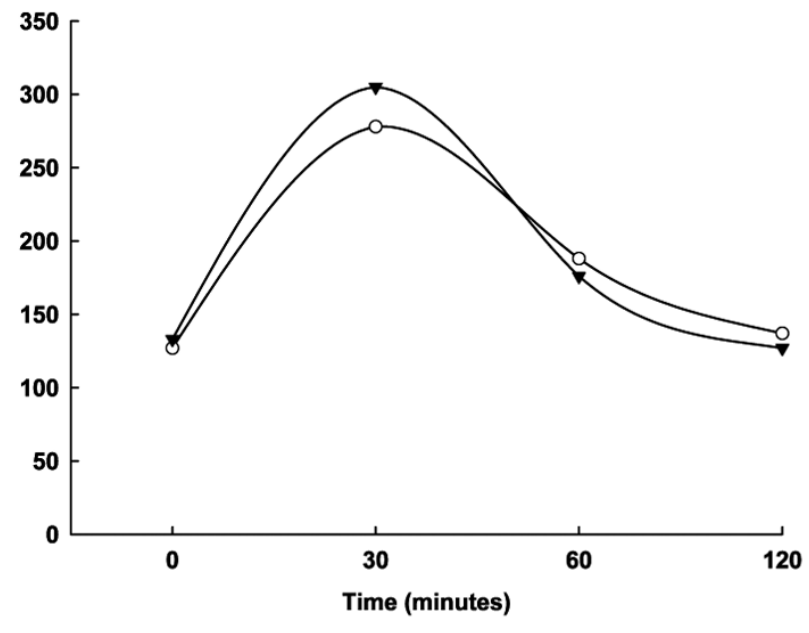

Fig. 1. IPGTTs 2 (A), 12 (B) and 56 (C) weeks after transplantation. Blood glucose profiles of Wistar rats transplanted with 2500 cryopreserved encapsulated CD rat islets $(\mathbf{\nabla} ; \mathrm{n}=$ $6)$ in comparison to glucose clearance kinetics of rats transplanted with non-cryopreserved encapsulated $\mathrm{CD}$ rat islets $(\mathrm{O} ; \mathrm{n}=6)$. Mean $\pm \mathrm{SE}$.

\section{Discussion}

We report for the first time long-term graft survival $(>1$ year) of cryopreserved encapsulated allogenic pancreatic islets in immunocompetent diabetic rats without immunosuppression.

As has recently been shown, long-term normoglycemia of type 1 diabetic patients can be achieved by allogenic human islet transplantation $[1,2]$. However, this technique requires the administration of immuno $\neg$ sup $\neg$ pressiva that are well-known to be associated with serious side effects. A bioartificial pancreas consisting of islets immunoprotected by an alginate microcapsule provides an alternative approach to overcome the rejection problem (10-12). In most of the studies islets were entrapped in $\mathrm{Ca}^{2+}$-cross-linked alginate-polylysine-alginate microcapsules according to the protocol of Lim and Sun (1980). Unfortunately, the results obtained by various groups using this microcapsule formulation in the last two decades were very inconsistent. Most importantly, graft survival was extremely random and was generally too limited for therapeutic applications of these microcapsules [1315]. The reasons for this are presumably the cytotoxicity of the polyamino acid and the mechanical instability of the microcapsules $[16,17]$. Microcapsules made of alginate cross-linked with $\mathrm{Ba}^{2+}$ do not share these disadvantages [18]. Duvivier-Kali et al. [7] have reported that such microcapsules protect islets against allorejection and autoimmunity. Furthermore, Omer et al. [8] found that $\mathrm{Ba}^{2+}$ cross-linked alginate microcapsules protect neonatal pancreatic cell clusters (NPCC's) when transplanted in the streptozotocin diabetic $\mathrm{Balb} / \mathrm{c}$ mouse model for 20 weeks. We have recently shown that use of highly purified and ultra high-viscosity alginates when cross-linked internally and externally together with $\mathrm{Ba} 2$ resulted in microcapsules of extremely high stability, particularly when proteins (e.g. human serum albumin) are incorporated simultaneously [19, 20, 21]. Moreover, we reported that islets entrapped in these novel capsules enable survival and function of adult rat and human islets in immunocompetent mice without immunosuppression for $>7$ months [4]. However, when dealing with allogenic islets, instead of xenogenic material (e.g. porcine islets), the shortage of islet tissue is a major problem. A reasonable concept to overcome these shortcomings is the cryopreservation and subsequent storage of microencapsulated allogenic islets, to allow their unlimited collection and use on demand. However, previous reports indicated that cryopreservation may lead to substantial losses of viability and functionality of non-encapsulated pancreatic islet cells $[22,24]$. In contrast, we reported recently a novel and gently cryopreservation protocol for rat islets encapsulated in alginate-based microcapsules [9]. Importantly, the cryopreserved encapsulated islets showed post thawing in vitro an insulin increase upon a glucose challenge comparable to that of non-cryopreserved encapsulated islets. Moreover, a stable short-term graft (4 weeks) function without the need of immunosuppression was detected after transplantation of 2500 cryopreserved encapsulated CD rat islets in streptozotocin-diabetic Wistar rats. However, to precisely assess the potential of this technique and to carry on this approach to human islets, long-term functionality data are highly warranted. Therefore, in this study we have transplanted 2500 cryopreserved alginate encapsulated CD rat islets in diabetic Wistar rats without immunosuppressiva and analysed the glucose profile of these animals for over 1 year. By these means, we have demonstrated that cryopreserved encapsulated islets maintained stable graft function for the whole duration of the study (some of the experiments are still ongoing), implying the long-term functionality of the graft, the absence of rejection and the stability of the microcapsules. This claim was strengthens by the finding that the pattern of glucose clearance during IPGTT's differed not from that of Wistar rats transplanted with non-cryopreserved encapsulated CD rat islets 2, 12 and 56 weeks after transplantation. This was also confirmed by studies of insulin secretion of some transplants explanted after 12 and 56 weeks. Taken together, the presented data demonstrate that cryopreserved encapsulated rat islets can reverse diabetes for a long period of time similarly to non-cryopreserved encapsulated rat islets without the need for immunosuppressiva. This is very promising because to our knowledge long-term graft function of cryoprserved encapsulated islets has not been reported in the literature. Future studies will now have to carry on this approach to human islets, aiming to apply such a bioartifical pancreas consisting of cryopreserved encapsulated islets in humans.

\section{REFERENCES}

1. Shapiro AM, Lakey JR, Ryan EA, Korbutt GS, Toth E, Warnock GL, et al. Islet transplantation in seven patients with type 1 diabetes mellitus using a glucocorticoid-free immunosuppressive regimen. N Engl J Med 2000;343: 230-38.

2. Ryan EA, Lakey JR, Paty BW, Imes S, Korbutt GS, Kneteman NM, et al. Successful islet transplantation: continued insulin reserve provides long-term glycemic control. Diabetes 2002;51:2148-57. 
3. Zhang N, Su D, Qu S, Tse T, Bottino R, Balamurugan $\mathrm{AN}$, al. Sirolimus is associated with reduced islet engraftment and impaired beta-cell function. Diabetes 2006;55: 2429-2436.

4. Schneider S, Feilen PJ, Brunnenmeier F, Minnemann T, Zimmermann H, Zimmermann U, et al. Long-term graft function of adult rat and human islets encapsulated in novel alginate-based microcapsules after transplantation in immunocompetent diabetic mice. Diabetes 2005;54: 687-693.

5. Schneider S, Feilen PJ, Slotty V, Kampfner D, Preuss S, Berger $S$, et al. Multilayer capsules: a promising microencapsulation system for transplantation of pancreatic islets. Biomaterials 2001;22:1961-1970.

6. Orive G, Hernández RM, Gascón AR, Calafiore R, Chang TM, De Vos P, et al. Cell encapsulation: Promise and Progress. Nature Medicine 2003;9:1104-1107.

7. Duvivier-Kali VF, Omer A, Parent RJ, O'Neil JJ, Weir GC. Complete protection of islets against allorejection and autoimmunity by a simple barium alginate membrane. Diabetes 2001;50:1698-1705.

8. Omer A, Duvivier-Kali VF, Trivedi N, Wilmot K, Bonner-Weir S, Weir GC. Survival and maturation of microencapsulated porcine neonatal cell clusters transplanted into immunocompetent mice. Diabetes 2003;52:69-75.

9. Schneider S, Klein HH. Preserved insulin secretion capacity and graft function of cryostored encapsulated rat islets. Regul Pept 2011;166:135-138.

10. Zimmermann U, Mimietz S, Zimmermann H, Hillgärtner M, Schneider H, Ludwig J, et al. Hydrogel-based non-autologous cell and tissue therapy. Biotechniques 2000;29: 564-581.

11. Zimmermann U, Cramer H, Jork A, Thürmer F, Zimmermann H, Fuhr G, et al. Microencapsulation-based cell therapy. In: Biotechnology, ed. Reed G, Rehm HJ, Eds. Weinheim, Wiley-VCH, 2001, p. 548-571

12. Zimmermann U, Hasse C, Rothmund M, Kühtreiber W. Biocompatible encapsulation materials: fundamentals and application. In: Cell Encapsulation Technology and Therapeutics, ed. Kühtreiber WM, Lanza RP, Chick WL, Eds. Boston, Birkhäuser, 1999, p. 40-52

13. De Vos P, Van Straaten JF, Nieuwenhuizen AG, de Groot M, Ploeg RJ, De Haan BJ, et al. Why do microencapsulated islet grafts fail in the absence of fibrotic overgrowth? Diabetes 1999;48:1381-1388.

14. King A, Lau J, Nordin A, Sandler S, Andersson A. The effect of capsule composition in the reversal of hyperglycemia in diabetic mice transplanted with microencapsulated allogeneic islets. Diabetes Technol Ther 2003;50: 653-663.

15. Krestow M, Lum ZP, Tai IT, Sun A. Xenotransplantation of microencapsulated fetal rat islets. Transplantation 1991;51:6651-6555.
16. Clayton HA, James RF, London NJ. Islet microencapsulation: a review. Acta Diabetol 1993;30:181-189.

17. De Vos P, Wolters GH, Fritschy WM, Van Schilfgaarde R. Obstacles in the application of microencapsulation in islet transplantation. Int J Artif Organs 1993 ;16:205-212.

18. Geisen K, Deutschländer H, Gorbach S, Klenke C, Zimmermann U. Function of barium alginate-microencapsulated xenogenic islets in different diabetic mouse models. In: Frontiers in Diabetes Research. Lessons from Animal Diabetes III, ed. Shafrir E, 1990, p. 142-148

19. Schneider S, Feilen P, Cramer H, Hillgartner M, Brunnenmeier F, Zimmermann $\mathrm{H}$, et al. Beneficial effects of human serum albumin on stability and functionality of alginate microcapsules fabricated in different ways. J Microencapsulation 2003;20:627-636.

20. Zimmermann H, Hillgartner M, Manz B, Feilen P, Brunnenmeier F, Leinfelder U, et al. Fabrication of homogeneously cross-linked, functional alginate microcapsules validated by NMR-, CLSM- and AFM-imaging. Biomaterials 2003;24:2083-2096.

21. Wolf R, Zimmermann D, Weber M, Feilen P, Ehrhart F, Salinas Jungjohann M, et al. Real-time 3-D dark-field microscopy for the validation of the cross-linking process of alginate microcapsules. Biomaterials 2005;26:6386-6393.

22. di Carlo A, Scharp DW, Gingerich RL, Giannarelli R, Ansara M, Olack BJ, et al. Insulin and glucagon release from isolated, perifused human islets following low temperature culture and cryopreservation. Transplant Proc 1994;26:821-822.

23. Rich SJ, Swift S, Thirdborough SM, James RF, Bell PR, London NJ. Islet cryopreservation: a detailed study of total functional losses. Transplant Proc 1994;26:823-824.

24. Lakey JR, Rajotte RV, Fedorow CA, Taylor MJ. Islet cryopreservation using intracellular preservation solutions. Cell Transplant 2001;10:583-589.

Received: February 28, 2011 / Accepted: May 31, 2011

Address for correspondence:

Stephan Schneider, MD

Department of Internal Medicine II

Diabetology and Endocrinology

Merheimer Str. 221-223

$50733 \mathrm{Köln}$

Germany

Phone: +49221 7712362

Fax: $\quad+492217712272$

E-mail: Stephan.Schneider@vinzenz-hospital.de 